\title{
Innovative Exploration and Practice of the Automatic Control Principle Course in University Artificial Intelligence Major
}

\author{
Lixia Liu ${ }^{1}$, Yu Zhang ${ }^{2}$, Rongwei Guo ${ }^{3}$, Huihong Zhao $^{4}$ \\ ${ }^{1,2,3,4}$ School of Mathematics and Statistics, Qilu University of Technology (Shandong Academy of Sciences), \\ Jinan 250353, China \\ ${ }^{1}$ lixialiu@qlu.edu.cn \\ 2zhangyu0707xu@gmail.com \\ ${ }^{3}$ rongwei_guo@163.com \\ ${ }^{4}$ huihong1980@163.com
}

\begin{abstract}
The automatic control principle (ACP) course is an important professional course for students of Artificial Intelligence (AI), which requires students' high comprehensive quality and practical operation ability, and requires teachers' rich teaching experience and advanced teaching techniques. In order to satisfy the characteristics of artificial intelligence major, the automatic control principle course needs to be innovated and reformed in two aspects, including teaching content and teaching mode. This paper firstly gives the existing teaching issues form two aspects for the ACP course regarding the outdated teaching content, outdate teaching method and single teaching mode. Then, aiming to the mentioned issues, we present the concrete innovation and practice measures. This mainly involves following three points: (1) The teaching contents of the ACP course should be consistent with the teaching program that be suitable for students of AI. (2) Teachers should adopt a mixed teaching mode that is the combination of online teaching and offline teaching. (3) The third suggestion is to consider the ideological and political elements factor into the ACP course, and feedback control is taken as an example to show how to appropriate introduce the factors into the course. Finally, the conclusion is presented.
\end{abstract}

Keywords: Automatic control principle, Artificial intelligence, Teaching content, Teaching mode.

\section{Introduction}

With the development of information technology and intelligence in modern society, various colleges and universities have begun to set up new majors of Artificial Intelligence (AI). In order to cultivate a group of students who master artificial intelligence professional technology, traditional modern control theory courses such as automatic control principle are still compulsory subjects for artificial intelligence majors. It is unrealistic for universities to develop entirely new professional courses for AI students. The most effective way is to reform and innovate existing courses, for the reason that the current teaching format and course content cannot fully meet the needs of AI students, it needs to mainly reform and innovate the course content and teaching mode according to the specialty characteristics.

At present, curriculum ideological and political teaching is of great significance in university teaching. The AI major involves the moral and ethical issues of artificial intelligence, such as: stealing the privacy of others through artificial intelligence technique through image recognition methods and information collection. Therefore, it is necessary to properly introduce the $\mathrm{c}$ of the course into the teaching of the course.

All in all, in order to explore the integration and innovation of traditional modern control theory courses in artificial intelligence major, in this paper, we take the classic automatic control principle as an example, firstly analyze the existing problems in the teaching of the ACP course, and put forward relevant constructive suggestions and schemes to improve the teaching quality from both teaching content and teaching mode.

\section{Existing Teaching Issues}

\subsection{Outdated Teaching Content}

As we all know, the automatic control principle course is a professional foundation course that with a higher professional level and greater difficulty in the learning process, even for the students of artificial intelligence major[1]. As it is a classic and traditional professional course, its curriculum content is very mature, and teachers are more inclined to directly apply the previous lectures in their class. But for the newly established artificial intelligence major, this kind of invariable content may not be appropriate for the students of AI. This is mainly because the ACP course involves considerable mathematical theory formula, which are difficult. On the other hand, if teachers only teach the outdated automatic control theory, students will also think that the course is not relevant to their major, so they will lose interest in learning.

\subsection{Outdated Teaching Methods}

Artificial intelligence (AI) is a major which conforms to the development of science and technology society, and its purpose is to train professionals for the era of AI. Moreover, the automatic control principle is an important specialized course, and its course content is also of great significance to the development of other specialized courses of Artificial Intelligence major, such as signals and systems, optimization methods, etc. But artificial intelligence is a major that pays more attention to practical engineering application, so the traditional pure theory teaching mode and method of automatic control principle is no longer suitable for this new major. Consequently, the innovative exploration for ACP course should be carried out to adapt to the development of 
the AI emerging majors.

\subsection{Single Teaching Mode}

In the past, the teaching mode of the ACP course was a combination of lectures and computer simulation. In my opinion, this teaching mode is too single and outdated. Furthermore, outdated teaching resources and a single teaching format, AI students will find it boring and difficult to learn when studying the ACP course. With the development of the current intelligent and networked era, combined with the current situation of the artificial intelligence profession, we should make full use of existing teaching resources and combine local resources to form a multi-mode hybrid teaching form.

\section{The Innovative Exploration and Practice Measures}

\subsection{Innovation of Teaching Content}

First of all, when we make training programs, appropriate teaching programs should be developed according to the characteristics of artificial intelligence. Secondly, due to the high professional content of the automatic control principle, which includes a lot of mathematical and control knowledge, students may find it difficult to understand in their learning process. It is known to us that a good start is the key to effectively completing the teaching task[2]. Therefore, in the first class, the teacher can enumerate common examples of automatic control in our life, especially those related to artificial intelligence manufacturing, and analyze their working principles and related theoretical knowledge of automatic control. Furthermore, the content of automatic control principle should be more in line with the professional characteristics of artificial intelligence.

\subsection{The Reform of Teaching Mode}

In terms of teaching mode, teachers should combine online and offline teaching modes. In the offline teaching time, the course content teaching should be about the application scenarios of artificial intelligence, and taken as an example to draw inferences from the traditional content. In the online course, teachers can fully use educational value-rich online knowledge resources to the automatic control principle learning. On the other hand, for Artificial intelligence (AI) students, more experiments and practical courses should be added to increase students' interest in learning. Last but certainly not the least, we should create conditions for AI students to participate in scientific and technological competitions related to artificial intelligence, and encourage them to visit and practice with the National Supercomputing Center, Artificial Intelligence Research Institute etc. We can also invite talents from enterprises to give lectures to students of artificial intelligence, so that they can not only master solid theoretical knowledge, but also learn relevant enterprise knowledge. Science and technology enterprises and society need comprehensive talents, so the teaching of automatic control principle course should realize the combination of theory and practice, and the combination of online and offline comprehensive teaching mode[3-4].

\subsection{The Ideological and Political Elements Factor is Introduced into the ACP Course}

The aim of curriculum ideological and political teaching is to comprehensively improve the talent training ability[5-7]. On the one hand, by introducing the curriculum thinking and politic into the ACP course of can make students more firm in their ideals and beliefs, which is in line with the national conditions of Chinese education. On the other hand, we should strengthen the ideological and moral construction for AI students, because with the advancement of science and technology, some artificial intelligence methods can steal the privacy, passwords and make illegal profits. Through ideological and moral construction, the occurrence of such things can be reduced. Thus, the curriculum ideological and political teaching is important in the AI students' education, we need to implement it in all aspects of curriculum target design, syllabus revision, textbook compilation and selection, and teaching plan courseware preparation, which runs through all links of classroom teaching, teaching and discussion, experimental and practical training, and homework papers. Taking the knowledge point of feedback control in the ACP course as an example, we will show how to integrate curriculum ideological and political content into class teaching.

For example: Feedback control refers to comparing the actual results after a certain action and task are completed, so as to have an impact on the next action and play a control role. Its characteristic is: to respond to the objective effect of each step in the implementation process of the plan decision in a timely manner, and adjust and modify the next implementation plan accordingly, so that the implementation of the plan decision is dynamic with the original plan itself reach coordination. In the process of feedback control, the control effect of the controlled object will adversely affect the control signal, which has an inhibitory effect on internal or external disturbance signals, the principle is shown in Figure 1.

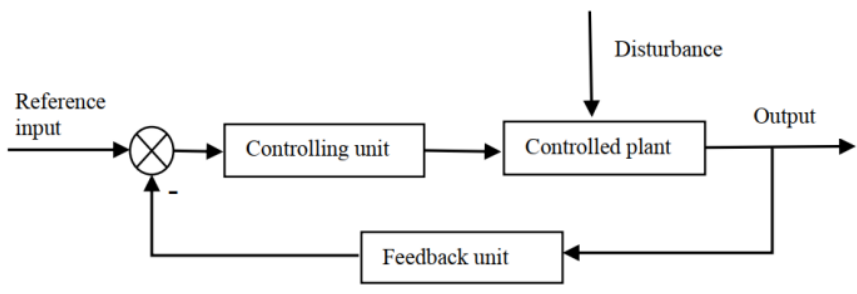

Figure 1: Feedback control block diagram

If we compare life to an automatic control system, we just move forward without looking back, just like open-loop control, it is impossible to correct deviations in the course of travel. Not forgetting the original intention of working hard, keeping in mind the dream of serving the country with science, and contributing to the scientific research of the motherland. This is the mission and responsibility of college students in the new era, and it is also the "Reference input" of the feedback control system, which can be shown as Figure 2 .

Finally, it is hoped that the ACP course can realize the curriculum goal of the interaction between teachers and students inside and outside of the classroom, constantly improve the ideological and political construction of the curriculum, and optimize the teaching. 


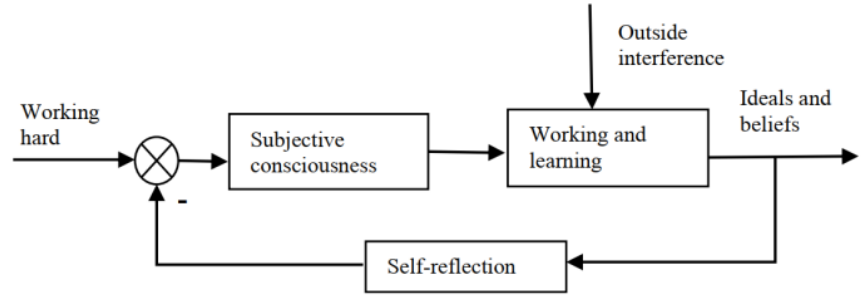

Figure 2: Working and learning feedback control block diagram

\section{Conclusion}

Under the background of science and education integration, it is our duty to promote the construction and practice of regional education community for new engineering talents in artificial intelligence. As an important and classic course of artificial intelligence major, the automatic control principle course needs to have innovative exploration of both teaching content and teaching methods to meet the high requirements of society and enterprises. Applying the above teaching mode, we can improve the interests in learning ACP course and strengthen the comprehensive quality of talents.

\section{Acknowledgments}

This work was partially supported by the second batch of new engineering research and practice specialty reform projects of the Ministry of Education (Project No. E-RCZN20201029), and "Talent training and promotion plan" project of computer science and technology discipline of Qilu University of Technology (Shandong Academy of Sciences) (Project No. 2021PY01006).

\section{Conflicts of Interest}

The authors declare that there is no conflict of interest.

\section{References}

[1] X. Li, S. Guo, "Innovative Exploration and Practice of the Single-chip Hybrid Teaching Model," Advances in Higher Education, 5(2), pp. 34-36, 2021.

[2] Y. Wang, "Discussion on the Training Mode of Applied Talents in Computer Science and Technology," Electronic Production, 000(018), pp. 92-92, 2015.

[3] W. Zhu, "Research on the Training Mode of Applied Talents in Computer Science and Technology," Western Education Research, 10(4), pp. 20-22, 2010.

[4] J. Hui, "Analysis on the Construction of Micro-video Online Course Resources in Colleges and Universities," Educational Modernization, (17), pp. 94-97, 2019.

[5] H. Wang. Theoretical and practical exploration of "curriculum ideological and political" reform in colleges and universities-Taking Mianyang Normal University as an example. Journal of Mianyang Normal University, 38(12), pp. 6-10, 2019.

[6] W Ge. Design and implementation of classroom teaching in higher vocational education under the concept of curriculum ideology and politics. Bohai University, 2021.
[7] Z Tan. An analysis of the academic logic of curriculum thought and politics. Journal of Higher Education, 7(26), pp. 185-188, 2021.

\section{Author Profile

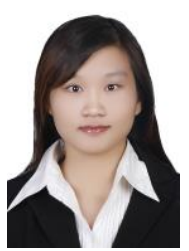

Lixia Liu received the B.S. degree in mathematics and the M.S. degree in operations research and cybernetics from the School of Mathematics and Statistics, Shandong Academy of Sciences, Qilu University of Technology, Jinan, in 2014 and 2016, respectively, and the Ph.D. degree from the Shanghai Institute of Applied Mathematics and Mechanics, Shanghai University, China, in 2020. She is currently a Lecturer with the School of Mathematics and Statistics, Shandong Academy of Sciences, Qilu University of Technology. Her research interests include dynamics and control of nonlinear systems, multi-agent systems, and multi-robot systems.

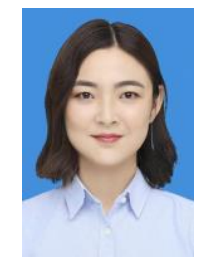

Yu Zhang received the B.E. degree in control science and engineering from Shandong University, Jinan, China, in 2014, and Ph.D. degree in Department of Electronic Engineering, The Chinese University of Hong Kong, Hong Kong, in 2019. She is currently a lecturer in Qilu University of Technology, Jinan, China. Her research interests include hyperspectral image segmentation and classifification.

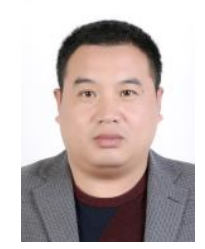

Rongwei Guo received the B.S. degree from the University of Jinan, China, in 2001, the M.S. degree from Shanghai University, China, in 2004, and the Ph.D. degree from Shandong University, China, in 2011. He is currently a Professor with the School of Mathematics and Statistics, Qilu University of Technology. His research interests include nonlinear systems control and switched systems.

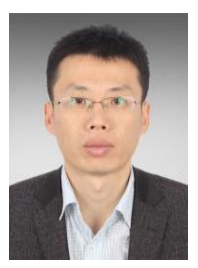

Huihong Zhao received his Ph.D. degree in Control Theory and Control Engineering from Shandong University in 2011. He is currently an associate professor at School of Mathematics and Statistics, Qilu University of Technology (Shandong Academy of Sciences), Jinan, China. His research interest covers curriculum system construction of artificial intelligence specialty, optimal control and estimation, and time-delay systems. 